\title{
Clínica-Palavra-Corpo: Afirmar o Que se Vive e Viver o Que se Afirma
}

\author{
Clínica-Palabra-Cuerpo: Afirmar lo Que se Vive Y Vivir lo Que se Afirma
}

Clinic-Word-Body: Affirm What One Lives and Live What One Affirms

Declaração de Direito Autoral

A submissão de originais para este periódico implica na transferência, pelos autores, dos direitos de publicação impressa e digital. Os direitos autorais para os artigos publicados são do autor, com direitos do periódico sobre a primeira publicação. Os autores somente poderão utilizar os mesmos resultados em outras publicações indicando claramente este periódico como o meio da publicação original. Em virtude de sermos um periódico de acesso aberto, permite-se o uso gratuito dos artigos em aplicações educacionais e científicas desde que citada a fonte conforme a licença CC-BY da Creative Commons.

Cleber Gibbon Ratto

ORCID: https://orcid.org/0000-0002-9059-728X

Centro Universitário Metodista, Rio Grande do Sul/Brasil

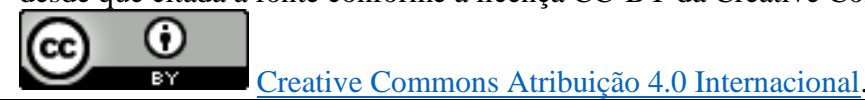

\section{Resumo}

O trabalho, construído através de um ensaio teórico, objetiva repensar a clínica psicanalítica a partir de problemáticas da sociedade atual. Pensando nas principais transformações sociais que afetam a subjetividade e as relações interpessoais, buscou-se identificar teorias e práticas que possam ser um contraponto ao desamparo contemporâneo. Voltando-se à escola húngara da psicanálise, foi possível investigar alguns conceitos de Ferenczi, de Winnicott e de Balint que propõem uma clínica afetiva e uma relação menos hierárquica entre analista e analisando. De tal maneira, proporcionando sustentação e possibilitando experiências de "novo começo". Além disso, trabalhando com a ideia de promover um modo de vida que faça sentido ao sujeito, realizou-se uma aproximação com os conceitos de cuidado de si e parresía de Foucault. Desse modo, integrando o entendimento psicanalítico ao olhar para si e à coragem de escandalizar a verdade no próprio corpo e na existência, buscou-se construir uma clínica crítica e criativa.

Palavras-chaves: Clínica psicanalítica; Contemporaneidade; Criatividade; Práticas de si.

\section{Resumen}

El trabajo se construye a través de un ensayo teórico y objetiva repensar la clínica psicanalítica a partir de problemáticas de la sociedad de hoy día. Pensando en lãs principales transformaciones sociales que afectan la subjetividad de las relaciones interpersonales, se buscó identificar teorías y prácticas que puedan ser un contrapunto al desamparo contemporáneo. Analisando la escuela húngara de psicanálisis, fue posible investigar conceptos de Ferenczi, de Winnicott y de Balint, que proponen una clínica afectiva y una relación menos hierárquica entre el que analisa y el que es analisado, lo que resulta sustentación y posibilidad de experiencias de "nuevo comienzo". Además, trabajando con la idea de promoción de un modo de vida que haga sentindo al sujecto, se hizo una aproximación con los conceptos de cuidado de uno mismo y de parresía, de Foucault. Así, mesclando la compreensión 
psicanalítica al mirar a uno mismo y el coraje de sorprender la verdade en el propio cuerpo y en la existencia, se buscó la construcción de una clínica crítica y creativa.

Palabras clave: Clínica psicoanalitica; Contemporaneidad; Creatividad; Prácticas de si.

\begin{abstract}
The work, constructed through a theoretical essay, aims to rethink the psychoanalytic clinic from the problematics of the current society. Thinking about the main social transformations that affect subjectivity and interpersonal relations, we sought to identify theories and practices that could be a counterpoint to contemporary helplessness. Turning to the Hungarian school of psychoanalysis, it was possible to investigate concepts of Ferenczi, Winnicott and Balint that propose an affective clinic and a less hierarchical relation between analyst and analyzing, providing support and enabling experiences of "new beginning". In addition, working with the idea of promoting a way of life that makes sense of the subject, an approach was approached with the concepts of care of self and parrhesia of Foucault. Thus, integrating psychoanalytic understanding by looking at oneself and the courage to scandalize the truth in one's own body and existence, one sought to construct a critical and creative clinic.
\end{abstract}

Keywords: Psychoanalytic clinic; Contemporaneity; Creativity; Practices of the self.

\section{Introdução}

Uma discussão contemporânea recorrente é sobre o quanto o tempo aparenta passar cada vez mais rápido, como se a rotina tornasse os dias iguais. Apesar de estarmos inseridos numa sociedade marcada pela informação, pela globalização e pela conexão, com constantes estímulos, parece que nada nos toca, poucas coisas nos mobilizam. Dentre as transformações sociais, a Revolução Industrial foi um grande marco que reconfigurou as relações de trabalho. Antes, a prevalência era de uma atividade manual e artesanal, na qual o produtor se constituía autor de sua obra. No processo de industrialização, ele passa a ser mão-de-obra em uma das etapas de fabricação, sem, muitas vezes, ter conhecimento do produto final, através de uma atividade repetitiva, na qual tende a não se apropriar dos resultados de seu trabalho.

Além disso, a era digital revolucionou a maneira como interagimos com a informação: a mídia nos bombardeia com manchetes em uma velocidade que nos faz consumir sem refletir tanto e as redes sociais oportunizaram interações virtuais e formas de exposição que alimentam uma banalização da imagem (Ratto, 2014).
Nesse contexto, após um longo período marcado pela rigidez e pela repressão, a sociedade se moderniza fragmentando as formas de poder antes vinculadas apenas às instituições, como nos mostra Foucault (2010) em seus estudos sobre o biopoder, ampliando as possibilidades de escolha, obviamente, sem abrir mão de certo controle. As estruturas sólidas vão dando lugar a uma modernidade líquida (Bauman, 1998), principalmente, através do crescimento das formas ditas "flexíveis" do capitalismo e do consumismo (Sennett, 1999). Sem a solidez e continuidade moderna, o sujeito se vê à deriva no mar de possibilidades e precisa ser capaz de "vestir e despir identidades" (Bauman, 1998, p. 23), adequando-se às exigências da sociedade de consumo marcada pela incerteza. Essas características se reproduzem nas relações que se tornam cada vez mais superficiais e ditadas pela busca do prazer imediato. De tal maneira, a "suposta criatividade, incessantemente promovida - na verdade, é uma obrigação de reagir sozinho ao próprio desamparo" (Mizrahi, 2017, p. 17).

É possível que esse modo de subjetivação (Foucault, 2010) leve o sujeito a uma crise, na qual sua existência perde o sentido. Ele repensa suas escolhas e motivações e pode se sentir paralisado, numa situação sem 
saída. O vazio existencial, na verdade cheio "de sensações novas que pedem passagem" (Rolnik, 2002, p. 6), pode gerar sintomas reais, transtornos, como depressão e ansiedade, e, consequentemente, levar ao suicídio, ao uso de substâncias ou à medicalização da existência, tão presentes na realidade atual.

Dentro desse contexto, podemos tomar como exemplo a temática do suicídio. Segundo a Organização Mundial da Saúde - OMS, em 2015, ocorreram cerca de 800.000 mortes por suicídio no mundo, sendo a segunda principal causa de morte para adolescentes e possuindo alto risco para idosos. Portanto, é imprescindível analisar essa realidade e buscar construir novos caminhos. Considerando o vazio como um espaço de devir, entre o nada e o ser (Canelas Neto, 2013), a escuta clínica não deve preenchê-lo, mas sim acolhê-lo, suportálo e torná-lo um espaço para potencialidades e uma abertura para novas possibilidades de existência.

Nesse sentido, a proposta foi mapear as possibilidades de uma clínica crítica e criativa, sob viés psicanalítico, que construa com o sujeito novas formas de se relacionar com a vida. Ao levar em conta a prevalência do sentimento de angústia devido à perda de fortes referências e à ascensão de discursos conservadores na atualidade, deve-se estar atento para não se submeter a discursos hegemônicos e moralistas.

A partir disso, tal pesquisa foi construída através de um ensaio teórico, entendendo-o como uma forma de se experimentar mais do que apenas uma ferramenta de escrita, um pensar sobre si que visa a transformação, estabelecendo-se uma certa distância de si mesmo e suspendendo-se valores em prol da reflexão (Larrosa, 2004). A crise discutida neste trabalho corrobora a escolha do ensaio como forma de voltar-se ao presente, levando-se em conta o contexto histórico, repensando "não a verdade de nosso passado, mas o passado de nossas verdades; não a verdade do que fomos, mas a história do que somos, daquilo que, talvez, já estamos deixando de ser." (Larrosa, 2004, p. 34). Dentro disso, produziu-se um diálogo com conceitos que se aproximam do objetivo proposto, por exemplo, a criatividade em Winnicott (2011), a clínica do novo começo de Balint (2014) e as noções de cuidado de si e parresía para Foucault (2004a; 2011), destacando-se as possíveis aproximações e os distanciamentos entre eles.

\section{Diferentes Críticas e Clínicas do Contemporâneo}

O inconsciente já não lida com pessoas e objetos, mas com trajetos e devires; já não é um inconsciente de comemoração, porém de mobilização, cujos objetos, mais do que permanecerem afundados na terra, levantam voo. (Deleuze, 1997, p. 75)

O contexto social atual parece desafiar a clínica tradicional - orientada pela interpretação do inconsciente recalcado - que já não dá conta das crises nas quais os sujeitos se encontram. Assim sendo, buscamos um outro recorte da psicanálise, mais especificamente a escola húngara reconhecida na figura de Sándor Ferenczi, para entender sua implicação nessa temática.

Ferenczi foi contemporâneo de Freud e um de seus seguidores até surgirem divergências teóricas e técnicas que lhe tornaram o "enfant terrible" (Ferenczi, 1931/1992a, p. 70 citado por Peres, 2008, p. 197) para o pai da Psicanálise. Atendendo grupos geralmente excluídos, como prostitutas, indigentes, homossexuais e casos considerados difíceis por ultrapassarem a neurose clássica, Ferenczi percebeu a necessidade de repensar a clínica psicanalítica. Sua proposta tem como base o afeto, possibilitando uma aproximação adequada entre analista-analisando e uma identificação por parte do terapeuta com os diferentes aspectos do sofrimento (Peres, 2008). Para isso, o autor ressalta a importância da disponibilidade do analista para tocar e ser tocado e da comunicação com a criança que há no paciente, tornando-se principal influência 
para Donald Woods Winnicott e Michael Balint - que serão abordados neste trabalho.

Donald Winnicott (1896/1971), além de psicanalista, foi um pediatra inglês que, portanto, teve sua atenção voltada para a relação mãe-bebê, entendendo o quanto essas experiências iniciais são de suma importância para o desenvolvimento do sujeito. O autor descreve a dependência mútua inicial, na qual é essencial uma preocupação materna primária característica da mãe ou do cuidador da criança que se identifica com o bebê, podendo captar o que ele sente (Winnicott, 2011).

Nesse período, o cuidador cria um ambiente adaptado às necessidades do bebê com o mínimo de resistência possível para suprir sua experiência de onipotência na qual ele cria o objeto e o sente como se fosse parte de si mesmo. A partir disso, a criança sente a necessidade de exercer sua criatividade em um mundo mais amplo que lhe apresente mais resistências. Então, o cuidador diminui os ajustes ao filho e apresenta uma realidade menos adaptada, permitindo que ele inicie um processo de diferenciação. Nesses momentos alternados, mais ou menos dependentes, o bebê pode afirmar simbolicamente uma separação ao mesmo tempo que a nega, construindo uma área entre o interno e o externo e estabelecendo uma experiência transicional.

Com a apresentação do princípio de realidade, a criança avança em suas relações objetais fazendo uso de um objeto externo capaz de ser odiado e diferenciado de si. É preciso que esse objeto externo também seja repleto de vitalidade e de criatividade para aplicar as resistências e os limites de modo acolhedor, sobrevivendo à destruição direcionada a ele (Mizhari, 2008).

Para um desenvolvimento saudável desse processo, é imprescindível uma mãe "suficientemente" boa, conceito que se estende ao principal cuidador da criança, que possa oferecer um suporte às necessidades do bebê ou o que o autor conceitua como holding, um "segurar" tanto físico, como na vida intra uterina, quanto esse cuidado adaptativo que está conectado às sensações do recém-nascido. O termo "suficiente" indica uma dosagem entre esse cuidado e as frustrações necessárias, um equilíbrio que se diferencia de um ambiente invasivo ou negligente. Assim, quando o sujeito pôde expressar sua agressividade e ser "segurado", compreendido, dando significado às suas experiências, ele se torna capaz de viver de forma criativa e busca se aproximar de contextos que lhe proporcionem essa liberdade.

Assim como Ferenczi, ao longo de sua prática, Winnicott se sentia incomodado com a ideia de que alguns casos, como os que apresentavam comportamentos delinquentes, tendências antissociais e as psicoses, não estariam aptos à psicanálise, reconhecendo limitações teóricas e técnicas. Além do importante conceito de espaço transicional, Winnicott ultrapassou o paradigma triangular freudiano construindo definições que fazem parte de sua teoria dual e maturacional (Loparic, 2007). O foco no desenvolvimento sexual dá lugar ao amadurecimento emocional, o qual está estritamente ligado à relação com o ambiente que se difere de uma relação sujeitoobjeto. Winnicott rejeita o dualismo pulsional freudiano, entendendo que o indivíduo não busca apenas o prazer nas relações, mas a presença e a confiança para satisfazer suas necessidades, inclusive, as de resistência.

Indo ao encontro de tais pensamentos, Michael Balint (1896/1970), psicanalista húngaro, também voltou seu olhar para as relações primárias do sujeito. Ao ter contato com pacientes considerados difíceis para as técnicas tradicionais psicanalíticas, ele percebeu a recorrência de sentimentos de inadequação, de estranheza e de dificuldade de serem eles mesmos que pareciam estar relacionados a traumas mais iniciais (Mello \& Herzog, 2008). O autor, entendendo que a subjetividade se constitui na interação com o outro, associou o bloqueio de tais pacientes de serem afetados nas relações a possíveis falhas no estágio do amor primário (Balint, 2014). Semelhante à construção teórica de Winnicott, o amor primário diz respeito à ligação do bebê com o ambiente, na qual os cuidadores adaptam suas necessidades às vontades da criança de 
forma prazerosa a ambos, estabelecendo uma relação de mutualidade e de interdependência entre eles. O recém-nascido expressa o desejo de ser amado plenamente, entretanto, o autor não denomina como sentimento de onipotência, uma vez que existe sintonia na interação. Nesse momento, há uma mistura do eu e do "não eu", na qual os cuidadores são identificados como substâncias primárias, sem um contorno e sem apresentar resistências, portanto, ainda não são vistos como objetos.

Logo, as necessidades do bebê se tornam mais complexas e ele amadurece emocionalmente para começar a compreender a externalidade do mundo. A mãe, ou o cuidador principal, começa a buscar outros interesses e fontes de prazer, dosando falhas e faltas na relação e considerando a capacidade de suportação de seu filho. Assim, as delimitações entre o interno e o externo ficam mais claras e a criança, na busca do bem-estar original, estabelece vínculos com o objeto. Nesse contato com a alteridade, o sujeito percebe que existem condições para ser amado e busca relacionamentos de cooperação em que ambos visam seu próprio prazer e também promover o prazer no outro, consolidando assim, o amor adulto (Mello \& Herzog, 2008).

Nesse contexto, um descuido precoce por parte dos objetos primordiais pode ser traumático para a criança promovendo futuras sensações de vazio, de inutilidade e até de morte, o que é conceituado por Balint (2014) como falha básica. A partir dessa falha, o sujeito pode se sentir negligenciado pelo ambiente ou se culpar, carregando o medo do abandono e a desconfiança em relação ao mundo ou a si próprio que precisa conter toda angústia sozinho.

Assim, serão formados modos rígidos de se relacionar nos quais a pessoa criaria uma realidade que necessita de total confiança em si ou nos outros, o que mais cedo ou mais tarde irá gerar frustração e, consequentemente, insegurança. Portanto, Balint (2014) acredita na possibilidade de um novo começo, através da experimentação de novas modalidades de relação, a partir do qual o sujeito constrói outras formas de ser e de estar no mundo. Essa transformação se dá nas relações e deve ser ofertada no setting clínico, sendo trabalhada na transferência analista-analisando.

Balint também apresenta distanciamentos da teoria freudiana, da qual foi bastante crítico. A noção de amor primário surge da recusa do conceito de narcisismo primário freudiano que diz respeito à fase entre o investimento em pulsões auto-eróticas e em relações de objeto, transformando a libido narcisista em libido objetal (Peixoto Junior, 2003). Para Balint, segundo Peixoto Junior (2003), todo narcisismo é secundário, uma vez que o indivíduo se volta para si como uma resposta ao fracasso do ambiente em saciar suas necessidades primárias, numa tentativa de resgatar a sensação de unidade. Portanto, o amor primário seria a forma mais primitiva de relação, na qual o bebê se funde às substâncias em um período de indiferenciação. Caracterizando-se sem zona erógena, a interdependência entre mãe-bebê pressupõe uma satisfação recíproca na qual o bebê acredita que ambos têm o mesmo desejo. Assim como o narcisismo, Balint também entende que as manifestações de ódio e de destrutividade são sempre secundárias, resultado de experiências ambientais negativas, logo, não trabalha com a definição de pulsão de morte (Peixoto Junior, 2003).

Tais autores rompem com a oposição dicotômica entre natureza e cultura, corroborada pelas teorias tradicionais da psicanálise, na qual a natureza é descrita como algo primário, selvagem, sem limites, e a cultura como algo elaborado, que produz ordem. Fazendo uma crítica a essa visão platônica, Martins (2009) nos sugere pensar "a cultura como um modo da natureza" (p. 21). Questiona se essa intervenção cultural a qual visa à domesticação do homem não seria também destrutiva, já que se impõe sobre o que é diferente baseada em um suposto consenso universal. Nesse sentido, ao rejeitar o conceito de pulsão de morte, Winnicott nega um suposto instinto antissocial do homem, despatologizando a vida. Dessa forma, rompe com a dicotomia indivíduo-sociedade, quando 
afirma que a coletividade não precisa temer a experiência afetiva individual singular e que a vida não precisa ser defendida dela mesma. Ao ampliarmos a relação inicial mãe-bebê ou cuidador-bebê para o contexto social, a teoria winnicottiana se apresenta enquanto um contraponto ao desamparo e às estratégias do biopoder, apresentadas por Foucault (2010), na busca pelo controle da vida. $\mathrm{Na}$ análise das últimas obras de Foucault, nota-se uma aproximação de seus conceitos com as ideias de Winnicott:

A discussão final de Foucault sobre uma ética ligada a formas de moderação, e estilos de vida onde as potências se encontram e se incitam mutuamente, independentemente de normas, códigos e controles, pode ser então aproximada em muitos aspectos da concepção de Winnicott de um viver criativo, que, quando se desenvolve bem a partir de relações cuidadosas, presentes no ambiente e internalizadas pelo sujeito, se desdobra em uma busca ética por espaços de criatividade compartilhada, onde as forças $\mathrm{e}$ vitalidades se encontram, independentemente dos controles normativos sobre os indivíduos. (Mizrahi, 2018, p. 70).

Tais proximidades e divergências teóricas serão aprofundadas ao longo deste trabalho, para isso seguiremos com uma breve exposição da teoria foucaultiana.

Michel Foucault (1926/1984), filósofo francês, passa por três grandes momentos ao longo de sua teoria. $O$ primeiro seria $o$ arqueológico, no qual o autor analisa os discursos de verdade atrelados a períodos históricos, estudando como eles se compõem, como influenciam os modos de pensar e como criam saberes. No segundo momento, genealógico, o objeto de análise serão as condições de possibilidade para o surgimento de determinados saberes e o quanto eles estão enredados em relações de poder que visam produzir subjetividades dóceis e controladas
(Galvão, 2014). Logo, o autor percebe que há resistência a esse controle sobre a vida e que há modos de ser que escapam da padronização. Assim, emergem novos pontos que serão estudados no terceiro momento, da estética da existência. Sem deixar de lado a dimensão histórica presente em suas primeiras obras, Foucault irá voltar-se à noção grega complexa do cuidado de si que ele denomina como "um certo modo de encarar as coisas, de estar no mundo, de praticar ações, de ter relações com o outro. A epiméleia heautô̂ (cuidado de si) é uma atitude - para consigo, para com outros, para com o mundo." (Foucault, 2004a, p. 14, grifos do autor). Seria um conjunto de práticas pelas quais o sujeito se transforma, buscando melhorar, então, para isso, deve-se converter o olhar para si e "estar atento ao que se pensa e ao que se passa no pensamento" (Foucault, 2004a, p. 14).

Percebendo que o que prevaleceu na filosofia foi o imperativo "conhece-te a ti mesmo", o autor retoma a Grécia Antiga através de filósofos como Sócrates e Platão para redesenhar a trajetória do cuidado de si. Sócrates afirmava que os deuses lhe ordenaram a incitar as pessoas a se ocuparem de si mesmas, para além dos bens materiais, sucesso e poder, colocando inquietude na existência. Com o advento do cristianismo, esse cuidado passa a ser visto como egoísmo e Gregório de Nissa, teólogo turco, sugere que se renuncie a si mesmo. Além disso, no "momento cartesiano", como Foucault (2004a) busca denominar o período de extrema racionalidade moderna, o conhecimento baseado em evidências predomina sobre o cuidado de si. "Pergunta-se 'o que é o homem?' e não mais 'quem sou eu?'" (Galvão, 2014, p. 164), ou seja, o sujeito precisa de conhecimento científico e não retomar as verdades que atravessam seu ser. As técnicas do cuidado de si vão sendo integradas a técnicas de autoridade, numa relação de saber/poder, isto é, os processos de subjetivação impõem padrões de como se deve viver, afastando a subjetividade de si mesma.

Quando questiona como criar um estilo de vida próprio, o autor entende que essas técnicas de si podem ser um contraponto às 
técnicas de dominação e às técnicas discursivas (Foucault, 2011). Através do cuidado de si, o sujeito está atento ao que pensa e seus pensamentos estão ligados às suas práticas, do mesmo modo que os discursos produzem ações. Portanto, quando ele fala sobre si, produz-se no seu discurso, trazendo à tona as verdades que o subjetivam. A atitude de falar por si sem separar palavra e ato, é trabalhada por Foucault (2004a) através do conceito da parresía. Tal conceito diz respeito a uma fala franca, pautada na liberdade de tudo dizer que consiste em abrir o coração de forma diferente de uma confissão na qual se espera o perdão. Não é uma opinião pessoal da boca para fora, mas sim ser capaz de assinar embaixo do que se diz (Foucault, 2011). É uma ética e uma técnica pela qual o sujeito se manifesta e pretende tornar-se soberano de si.

No modelo grego, a parresía se dá entre o mestre, que se mostra verdadeiro e não artificial, e o discípulo, que escuta e transforma a si e a seu discurso de verdade. Esse mestre precisa ter a prática da fala franca que afeta seu ouvinte, possibilitando que ele faça uso de seu discurso e também tenha direito de falar livremente (Foucault, 2004a). Logo, há uma diferenciação desse processo com a retórica, pela qual se tenta convencer o outro, e a lisonja, que consiste em reforçar a superioridade do outro para obter vantagens mesmo através da mentira. Na parresía, não se pretende dar instruções e manter o ouvinte dependente, já que se espera que ele conheça a si mesmo de forma autônoma. Essa manifestação carrega o risco de ferir e de desfazer a relação com o outro, que é a condição para o discurso. Portanto, a parresía prevê a coragem da verdade (Foucault, 2011), coragem por parte de quem se arrisca a falar as verdades e de quem aceita ouvi-las com todas suas consequências dolorosas de transformação. $\mathrm{O}$ autor realiza um agrupamento de momentos da parresía, o helenístico, o político, o socrático e a parresía cínica, a qual teria maior ligação entre a verdade e o modo de vida. A ética cínica testa até que ponto as verdades suportam ser vividas, reduzindo todas convenções sociais inúteis e opiniões supérfluas, fazendo da existência ponto de manifestação da verdade (Foucault,
2011). Os cínicos praticavam o escândalo da verdade, testemunhando-a no próprio corpo.

Ao analisar as aproximações entre Foucault e a psicanálise, percebe-se que ela foi um objeto de estudo quase constante ao longo de sua obra. No período de estudos que compõe uma arqueologia do saber, o autor entende que a psicanálise aparenta seguir uma lógica de que detém o saber sobre a loucura e sobre o sujeito ao mesmo tempo em que promove o descentramento do eu racional através do conceito de inconsciente (Birman, 2000). Já em sua genealogia do poder, Foucault critica a falsa promessa da psicanálise em libertar o sujeito das amarras da repressão sexual, uma vez que, através da confissão da sexualidade, do exame de consciência, da universalização do complexo de Édipo e da constituição do superego baseado em leis morais, ela segue trabalhando com a promoção da culpa (Birman, 2000). Dessa forma, caracteriza-se como uma modalidade do poder disciplinar, docilizando os corpos, corrigindo desvios, produzindo subjetividades homogêneas e padronizadas, como uma continuação do poder psiquiátrico (Ventura, 2012).

Nesse tratamento moral da loucura, a psicanálise se coloca numa relação vertical de saber/poder com o "doente" que nada sabe. Foucault demonstra que, na tradição trágica, a loucura é entendida como desrazão, uma forma de ser sem interioridade com fronteiras fragmentadas com o fora, entendendo-a como uma experiência de enunciação da verdade (Birman, 2000). Ou seja, a psicanálise pode permitir-se ser atravessada por essas outras lógicas, estando atenta às estruturas de poder e aos jogos de verdade. Não sendo uma ciência restrita, ela se aproxima de características das práticas espirituais da Antiguidade, que preveem a transformação do sujeito para o acesso à verdade (Giacoia, 2017). Portanto, a clínica pode ir ao encontro de uma estilística da existência, promovendo no cuidado uma transformação de si e a experimentação de outros modos de vida. Deve buscar diferentes destinos para as pulsões, saindo do erótico para produzir novas verdades sobre si e construindo uma responsabilização do sujeito nessa busca 
por outras formas de se subjetivar (Ventura, 2012). Dessa maneira, quando a psicanálise se implica no uso da resistência dos sujeitos para a emancipação e a busca de liberdade (Giacoia, 2017), pode tornar-se uma aliada teórica para o trabalho de Foucault.

\section{Clínica-Palavra-Corpo: Entre Afirmar o Que se Vive e Viver o Que se Afirma}

Em um post, feito em um grupo de uma rede social", intitulado "confissões da madrugada", foi constatado que grande parte dos comentários trazia sofrimento em relatos como "estou cansado de viver", "enjoada de viver", "não consigo me imaginar tendo relacionamento sério com alguém, porque acho que nunca mais vou confiar em alguém", "é um vazio dentro de vários", entre outros. Apesar de ser um grupo fechado, a urgência de expor queixas com desconhecidos na internet nos fala dos sintomas contemporâneos.

Os sujeitos se veem desamparados e solitários, tendo que resolver suas necessidades sozinhos, evidenciando a fragilidade dos vínculos (Mizrahi, 2010). A desconfiança se torna comodismo e conservadorismo, resultando numa falta de apetite existencial e em pouco investimento afetivo nas relações (Figueiredo, 2007). A sensação de não pertencimento é recorrente na atualidade e o mal-estar está aquém de uma representação, pois, muitas vezes, não há símbolo para o ocorrido e a narrativa se torna esvaziada. Portanto, é necessário construir uma clínica política no sentido de se estar atento às questões sociais e culturais, pautando-se em uma ética do cuidado enquanto contraponto à superficialidade das relações e dos afetos. Além disso, é imprescindível proporcionar no setting a possibilidade do paciente se entregar novamente ao amor, ao prazer, como na primeira infância.

\footnotetext{
${ }^{1}$ Grupo privado de uma rede social, no qual grande parte dos integrantes são jovens que postam sobre temas do cotidiano, assim como questões políticas sobre feminismo, racismo e lgbtfobia. Postagens denominadas "confissões da madrugada" são apagadas em menos de 24 horas.
}

O homem hipermoderno parece transitar entre a neurose e a psicose (Lejarraga, 2013) não se caracterizando mais como o neurótico clássico, reprimido e moralista, dos estudos de Freud. Dessa forma, para repensar a implicação da psicanálise nesse processo, é imprescindível um olhar atento à transferência e às técnicas tradicionais. Dentre os encontros possíveis durante o estágio profissionalizante ${ }^{2}$, um caso em especial propiciou a busca, na psicanálise, por outras formas de conexão que ultrapassavam os limites da abstinência e da frieza emocional por parte do analista. Através de uma relação horizontal com a paciente, foi possível oferecer mais acolhimento e sustentação do que neutralidade, a partir de uma escuta sensível.

Para Ferenczi (Borges, 2015), a frieza por parte do analista frente à crise do paciente pode funcionar como o desmentido, desvalidando o sentimento e gerando traumas. $\mathrm{O}$ analista corre o risco de se inserir numa relação de poder, mantendo o paciente submisso, falando sobre ele e não com ele, promovendo um "falso self". Quando o paciente não tem meios para recusar uma sugestão interpretativa e sua recusa é desvalidada ele se vê em uma relação violenta, sem possibilidade de conduzir sua ação e resistir. Em alguns casos, o divã pode ser usado mais para manter a neutralidade do terapeuta a salvo, uma vez que ele vê sem ser visto, semelhante a um panóptico (Mello \& Herzog, 2008). Isto é, existem casos em que o olhar do paciente precisa da sustentação do olhar do analista, como no encontro com a paciente L., no qual sem a palavra falada a atenção voltouse a outras linguagens, instaurando uma ligação, inclusive, corporal, na qual o analista sente e ouve seu próprio corpo.

Apesar dos 18 anos, a paciente parecia estar regredida com aparência e comportamentos infantis. Da mesma forma, os

\footnotetext{
${ }^{2}$ Estágio Profissionalizante realizado no Serviço Escola de Psicologia do IPA no ano de 2017, tendo como prática acolhimentos, atendimentos individuais e em grupo, supervisionado sob a perspectiva psicanalítica.
} 
pré-adolescentes do grupo terapêutico coordenado no mesmo local de estágio apresentavam a necessidade de voltarem à infância com brincadeiras e jogos que não costumavam mais jogar. Nesse sentido, a regressão não está sendo vista como uma resistência, mas como uma possibilidade de retornar a um momento de fragilidade e, a partir dele, reconstruir a si e a forma de se relacionar, como entende Balint (2014). Em tais casos, predominava uma dificuldade no relacionamento com os pais e, de certa forma, foi ofertado um espaço onde poderiam ter diferentes pais e serem diferentes filhos. É importante que o paciente possa experimentar novas relações objetais para restaurar a confiança e, assim, abrir-se para o outro, transformando, de forma criativa, os objetos em parceiros (Mello \& Herzog, 2008). Porém, é preciso ter cautela para reviver os traumas de forma que não se produzam novos traumas na transferência. Para isso, é fundamental estabelecer um clima de confiança em que o terapeuta sobreviva aos ataques do paciente e adapte-se às suas necessidades como um cuidador da primeira infância. Buscando entrar em contato com a parte infantil que foi clivada, o analista se coloca enquanto objeto transicional que é externo e que também é criado pelo paciente (Nina, 2007). Portanto, na transferência, não há necessidade de confrontar o paciente com a falta, e sim oferecer facilitação (Mizrahi, 2008). Seria um reconhecimento da falta na presença do outro, um “estar só na presença de alguém" (Winnicott, 1983, p. 37). Assim, com a paciente L., foi importante suportar seus silêncios e segurar-lhe afetivamente para que pudesse se separar da mãe simbiótica e se entender enquanto sujeito que fala por si. Nesse difícil novo começo, ela pode avançar no desenvolvimento e se permitir sentir coisas novas, mostrando incríveis transformações em um curto espaço de tempo.

Nesse sentido, não se deve ajustar o paciente à teoria, mas lançar mão de diferentes entendimentos e técnicas que se aproximem das suas peculiaridades. O terapeuta precisa se desvencilhar da rigidez das escolas psicanalíticas, trocando o "ou" pelo "e", para não transformar uma teoria em doutrina (Figueiredo, 2009). Por exemplo, o foco excessivo na interpretação enquanto principal técnica pode servir mais às necessidades narcísicas do analista do que ao andamento do tratamento. Uma interpretação sem holding seria o conhecimento puro sem cuidado, imposto de fora, sem a criação de uma realidade em conjunto (Mizrahi, 2010). Antes, é imprescindível que o terapeuta esteja mergulhado nas afecções e aberto às sensações para fazer aparecer o que não aparecia, ou seja, "deve entrar no círculo das representações emocionais do seu cliente, como quem entra em cena numa peça teatral que não é de sua autoria e cujos diálogos ainda desconhece." (Herrmann, 2001, pp. 201-202 citado por Frayze-Pereira, 2007, p. 135). Dessa maneira, deve esperar a evolução natural da transferência para que o paciente entre em contato com uma parte sua no seu ritmo. Por isso, é possível comparar o processo de interpretação a um parto no qual se espera que a natureza faça sua parte, trazendo à vida um bebê e não um fórceps, isto é, que surja um sentido e não um instrumento teórico (FrayzePereira, 2007). Portanto, a interpretação é feita a quatro mãos, desenvolvendo-se na intersubjetividade analista-analisando (Nina, 2007), na qual o terapeuta pode mostrar o que compreendeu e devolver isso ao paciente. Assim, o espaço analítico seria, não de assujeitamento, mas de "propor sentidos, variálos, fazê-los trabalhar uns com os outros e contra os outros" (Cavalcanti, 2012, n.p).

Em tal contexto, o analista precisa estar presente fazendo com que o seu existir na relação terapêutica possibilite o existir do outro, aproximando-se do conceito de espaço transicional para Winnicott e da amizade para Ferenczi e Foucault (Mizrahi, 2010). Na amizade, há um encontro afetivo com a alteridade no qual os sujeitos exercem sua criatividade e oferecem limites saudáveis para a expansão do outro, escapando da padronização das relações. Nesse potencial transgressivo da amizade, em que um se intensifica no contato com o outro, exerce-se 
um holding mútuo (Mizrahi, 2010). Assim sendo, pode-se dizer que o amigo, para Foucault, aproxima-se do conceito da mãe suficientemente boa de Winnicott e o insere nas relações sociais e políticas enquanto espaço para troca, criação, liberdade e sustentação (Mizrahi, 2010). Esse espaço intersubjetivo pode ser entendido enquanto "uma forte fonte de resistência às concepções de autonomia modernas, ligadas às tentativas do biopoder de reduzir o risco e multiplicidade da vida às identidades universais rígidas, baseadas na imposição de normas sobre indivíduos supostamente anti-sociais" (Mizrahi, 2018, pp. 88-89).

Ainda dentro das aproximações com a teoria foucaultiana, da mesma forma que o ego winnicottiano tenta desviar de situações que levariam à violência ou ao descuido, o cuidado de si de Foucault também se norteia por contextos que permitam exercer seu poder, sem se prender a circunstâncias adversas (Mizrahi, 2010). Apesar disso, Foucault parece defender uma subjetividade que não se fixa e está totalmente aberta, enquanto Winnicott aponta que precisamos manter uma certa continuidade para nos reconhecermos e para reconhecermos o outro mesmo que através de identidades provisórias e passíveis de mudança (Mizrahi, 2010). Assim como, para as práticas do cuidado de si foucaultianas, a violência e o comportamento disruptivo são considerados uma reação passiva que diminuem a potência do ser; para Winnicott, eles podem ser a imposição das necessidades do sujeito em um ambiente hostil, uma vez que os modos de resistência dependem de um ambiente facilitador. Apesar das críticas à psicanálise, Foucault reconhece uma possibilidade emancipatória através do devir revolucionário das pessoas, portanto, a psicanálise deve visar o devir e a singularidade (Giacoia, 2017).

De tal maneira, a clínica necessita estar aberta aos fluxos desterritorializantes (Borges, 2015), ou seja, entendendo que o devir está preso nos sintomas, o encontro clínico deve produzir novos devires, para que através desse processo o sujeito alcance momentos de liberdade para esculpir sua vida com uma obra de arte (Galvão, 2014), escapando dos padrões que lhes são impostos. Sendo assim,

Um processo que não remete necessariamente a nenhum complexo universal a respeito da subjetividade, mas que forja sua própria cartografia ao permitir que o indivíduo, de acordo com as situações, reconstitua territórios existenciais lá onde ele se encontrava angustiado e quase desintegrado, reconstruindo ao mesmo tempo suas relações com o mundo de acordo com novas possibilidades de viver. (Peixoto Junior, 2013, p. 336).

À vista disso, o sujeito poderia se tornar mais saudável, entendendo a saúde não como ausência de doença, pois estar doente faz parte da existência, mas como a possibilidade de agir ativamente sobre sua vida, criando formas de relação com o ambiente, recusando-se a simplesmente adaptar-se, identificando-se com a sociedade sem abrir mão do self (Rodrigues \& Peixoto Junior, 2014). Assim sendo, sua criatividade não ficaria restrita à fantasia, uma vez que usaria suportes reais presentes no ambiente para se expressar (Mizrahi, 2010).

Muitas patologias atuais surgem como efeito da tentativa de preencher o sentido psicológico para não permitir que o vazio impulsione a invenção (Rolnik, 2002), portanto, participar da construção de sua existência promove no sujeito o sentimento de que a vida vale a pena ser vivida. Entendendo alguns sintomas contemporâneos como resistência aos processos de subjetivação, a clínica deve acolhê-los, permitindo uma experiência transicional que visa inspirar movimentos que fujam das condições de desamparo. Assim, a clínica pode ser um dispositivo micropolítico quando, a partir desse encontro suficientemente bom, aumentar a participação política do sujeito, fazendo com que afetem também as pessoas com quem se relaciona (Mizrahi, 2010).

\section{Considerações finais}


Sem um olhar nostálgico e negativo sobre as formas de se relacionar contemporâneas, podemos despatologizá-las e entendê-las enquanto parte da cultura passíveis de transformação. A liberdade atual nos aproxima dos artistas aos quais era reservada a dimensão estética, permitindo-nos experimentar os prazeres e as emoções para a criação e para a transformação da existência, ou seja, tornarmo-nos artistas de nossas próprias vidas (Martins, 2013). Ao levar em conta o "paradoxo winnicottiano de que a novidade criativa só pode emergir em contextos que oferecem certa medida de permanência" (Mizrahi, p. 194, 2010), entendemos que a vida se dá por fluxos de territorialização, de desterritorialização e de reterritorialização (Deleuze \& Guattari, 1995), estabelecendo a continuidade da existência.

Nesse processo, é importante que o sujeito seja crítico de si mesmo para que haja uma coincidência entre seus atos e suas palavras, que ele confie na sua verdade, aplicando-a à sua existência, colocando-se em uma relação de transformação recíproca com a verdade, a qual se personaliza no sujeito que se expõe na verdade (Fimiani, 2004), falando em seu nome e referindo-se a uma situação atual singular. Sendo assim, essa transformação também diz respeito ao cuidado de si, exercendo uma "atitude exigente, prudente, experimental: confrontar o que se pensa e o que se diz com o que se faz e o que se é" (Foucault, 2004b, p. 219). Portanto, podemos recusar o que somos, colocando-nos em questão, criticando e reparando nossos valores de forma construtiva e transformadora.

Cavalcanti (2012) nos fala em pensar a experiência psicanalítica como uma experiência parresiástica de dizer verdadeiro num contexto de liberdade quando o analista, tão atravessado por campos de força quanto o analisando, desprotegido de uma verdade que detém, se coloca como sujeito do enunciado, dando opinião sobre o que diz tornando sensível seu próprio psiquismo em movimento. Considera-se que o analisando também exerce poder sobre o terapeuta na transferência, buscando equilibrar sua potência em relação a ele e exercer sua própria potência. Nessa clínica na qual não há verdade última nos sujeitos, o analista enuncia verdades que se produzirão nele a cada momento a partir do que o analisando diz e se responsabiliza por elas, mantendo-as abertas à mudança nesse jogo de forças que se desdobra no campo de interlocução. Por sua vez, o analisando fala ou silencia movido pelas forças pulsionais impactadas pelo dizer do analista (Cavalcanti, 2012).

Quando o sujeito realiza a prática de se desconstruir e de falar sobre si de forma franca, parresía, ele permite se reinventar e devir outros (Borges, 2015). Analisando os atravessamentos externos que constituem seu modo de ser, pode escolher por verdades que menos sufocam sua subjetividade (Marcello \& Fischer, 2014). De tal maneira, o analista pode auxiliar nessa conversão do olhar para si e para suas verdades e provocar um estranhamento. Figueiredo (2009 citado por Silva Sobrinho, 2015) nos fala de uma metapsicologia do cuidado que compõe o trabalho do terapeuta: acolher, sustentar e garantir continuidade; reconhecer a singularidade e devolver ao sujeito e fazê-lo se questionar, pensar e construir uma narrativa sobre si e sobre seu mal-estar. Nesse sentido, o cuidar de si não está ligado ao corpo biológico, o qual é o foco do consumismo que vende imagens de corpos saudáveis e em forma, ao mesmo tempo em que o desvaloriza. O cuidado de si, pautado em um ambiente facilitador e atravessado pela coragem da verdade, é um contraponto ao biopoder e ao desamparo. É uma resistência política que se realiza no processo de autocriação, apoiado nas relações sociais (Mizrahi, 2010). Assim, através de uma existência crítica e criativa, o sujeito pode atribuir novos sentidos a ela, buscando afirmar o que vive e viver o que afirma. 


\section{Referências}

Balint, M. (2014). A falha básica: aspectos terapêuticos da regressão. São Paulo: Zagodoni.

Bauman, Z. (1998). O mal-estar na pósmodernidade. Rio de Janeiro: Jorge Zahar Ed.

Birman, J. (2000). Entre cuidado e saber de si: sobre Foucault e a psicanálise. Rio de Janeiro: Relume-Dumará.

Borges, H. (2015). O campo sutil do encontro: metacorporeidade e a clínica. Semina: Ciências Sociais e Humanas, 36(1), 79-94. doi: 10.5433/1679-0383.2015v36n1p79

Canelas Neto, J. M. (2013). Reflexão sobre o vazio dentro da psicanálise: do horror do vazio ao vazio criador de metáforas. Jornal de Psicanálise, 46(85), 127-140.

Recuperado de

http://pepsic.bvsalud.org/scielo.php?script= sci_arttext\&pid=S010358352013000200013\&lng $=p t \& t \operatorname{lng}=p t$

Cavalcanti, M. M. T. (2012). Psicanálise e dizer verdadeiro: Proposições acerca da escuta psicanalítica do mal-estar na contemporaneidade. Revista EPOS, 3(2).

Recuperado de http://pepsic.bvsalud.org/scielo.php?script= sci_arttext\&pid=S2178700X2012000200002

Deleuze, G. (1997). Crítica e clínica. São Paulo: Editora 34.

Deleuze, G., \& Guattari, F. (1995). Mil platôs: capitalismo e esquizofrenia (Vol 2). Rio de Janeiro: Editora 34 Ltda.

Figueiredo, L. C. (2007). Confiança: a experiência de confiar na clínica psicanalítica e no plano da cultura. Revista Brasileira de Psicanálise, 41(3), 69-87.

Recuperado de

http://pepsic.bvsalud.org/scielo.php?script= sci_arttext\&pid=S0486-

641X2007000300008

Figueiredo, L. C. (2009). A psicanálise e a clínica contemporânea. Contemporânea Psicanálise e Transdisciplinaridade, (7), 917. Recuperado de http://www.revistacontemporanea.org.br/re vistacontemporaneaanterior/site/wpcontent/artigos/artigo202.pdf

Fimiani, M. (2004) O verdadeiro amor e o cuidado comum do mundo. In F. Gros (Org.), Foucault: a coragem da verdade. São Paulo: Parábola Editorial.

Foucault, M. (2004a) A hermenêutica do sujeito. São Paulo: Martins Fontes.

Foucault, M. (2004b) Política, e ética: uma entrevista. In M. Foucault. Ética, sexualidade, política. Rio de Janeiro: Forense Universitária.

Foucault, M. (2010) Em defesa da sociedade: curso no Collège de France (2ed.). São Paulo: Editora WMF Martins Fontes.

Foucault, M. (2011). A coragem da verdade. São Paulo: Martins Fontes.

Frayze-Pereira, J. A. (2007). Da arte de interpretar o paciente como obra de arte. Jornal de Psicanálise, 40(73), 133-144. Recuperado de http://pepsic.bvsalud.org/scielo.php?script= sci_arttext\&pid=S010358352007000200012

Galvão, B. A. (2014). A ética em Michel Foucault: do cuidado de si à estética da existência. Intuitio, 7(1), 157-168. doi: 10.15448/1983-4012.2014.1.17068

Giacoia, O., Jr. (2017). Para revisitar o tema: Foucault e a psicanálise. Doispontos, 14(1), 135-143. Recuperado de https://revistas.ufpr.br/doispontos/article/vi ew/56544/34026

Larrosa, J. (2004). A Operação Ensaio: sobre o ensaiar e o ensaiar-se no pensamento, na escrita e na vida. Revista Educação e Realidade, 29(1), 27-43. Recuperado de https://seer.ufrgs.br/educacaoerealidade/arti cle/view/25417

Lejarraga, A. L. (2013). O homem transicional: para além do neurótico \& borderline. Cadernos de Psicanálise CPRJ, 35(28), 205-209. Recuperado de http://pepsic.bvsalud.org/scielo.php?script= sci_arttext\&pid=S141362952013000100012

Loparic, Z. (2007). De Freud a Winnicott: aspectos de uma mudança paradigmática. 
Contemporânea - Psicanálise e

Transdisciplinaridade, (1), 27-45.

Recuperado de

http://pepsic.bvsalud.org/scielo.php?script= sci_arttext\&pid=S1679-

432X2006000100004

Marcello, F. A., \& Fischer, R. M. B. (2014).

Cuidar de si, dizer a verdade: arte,

pensamento e ética do sujeito. Pro-

Posições, 25(2), 157-175.

doi: $10.1590 /$ S0103-73072014000200009

Martins, A. (2009). Pulsão de morte? Por uma clínica psicanalítica da potência. Rio de Janeiro: Editoria UFRJ.

Martins, A. (2013). Prefácio. In: Armony, N. O homem transicional: para além do neurótico \& borderline. São Paulo: Zagodoni.

Mello, R. \& Herzog, R. (2008) Subjetividade e defesa na obra de Michel Balint. Revista mal-estar e subjetividade, 8(4), 1121-1142.

Recuperado de

http://pepsic.bvsalud.org/scielo.php?script= sci_arttext\&pid=S151861482008000400012

Mizrahi, B. G. (2008). O resgate dos afetos em Winnicott: um contraponto ao biopoder e ao desamparo na atualidade. Cadernos de Psicanálise - CRPJ, (21), 233-251.

Recuperado de http://cprj.com.br/imagenscadernos/caderno 21 pdf/15Cadernos\%20n.\%2021_O\%20res gate $\% 20 \mathrm{dos} \% 20 \mathrm{afetos} \% 20 \mathrm{em} \% 20 \mathrm{Winnico}$ tt.pdf

Mizrahi, B. G. (2010). A vida criativa em Winnicott: um contraponto ao biopoder e ao desamparo no contexto contemporâneo. Rio de Janeiro: Garamond.

Mizrahi, B. G. (2017). Winnicott, Kohut e a teoria da intersubjetividade: uma psicanálise do pertencimento frente à precariedade contemporânea dos vínculos. Cadernos de Psicanálise - CRPJ, 39(36), 11-29. Recuperado de http://cprj.com.br/imagenscadernos/caderno 36_pdf/1_Winnicott-Kohut-e-a-teoria-daintersubjetividade.pdf

Mizrahi, B. G. (2018). Mizrahi, B. G. (2018). Foucault e Winnicott: a vida criativa como contraponto ao biopoder. Revista Trágica: estudos de filosofia da imanência, 11(1), 68-93. Recuperado de

https://revistas.ufrj.br/index.php/tragica/arti cle/view/27202

Nina, M. D. (2007). Re-desenhando com Winnicott: a interpretação encarnada. Jornal de Psicanálise, 40(73), 157-168. Recuperado de http://pepsic.bvsalud.org/scielo.php?script= sci_arttext\&pid=S010358352007000200014

Organização Mundial da Saúde [OMS]. (2015). Dados do Observatório da Saúde Global. Recuperado em 01 setembro, 2017, de

http://www.who.int/gho/mental_health/en/

Peixoto Junior, C. A. (2003). Do narcisismo ao amor primário: Balint e a gênese dos processos de subjetivação. Psychê, (11), 13-28. Recuperado de http://www.redalyc.org/html/307/30701102

Peixoto Junior, C. A. (2013). Amizade e ética do cuidado em psicanálise. Psicologia USP, 24(2), 333-337. doi: 10.1590/S010365642013000200009

Peres, F. S. (2008). Sándor Ferenczi: fragmentos de uma clínica do afeto. Cadernos de Psicanálise - CPRJ, 21, 193207. Recuperado de http://cprj.com.br/imagenscadernos/caderno $21 \_$pdf/12Cadernos\%20n.\%2021_S\%C3\% A1ndor\%20Ferenczi.pdf

Ratto, C. G. (2014). Enfrentar o vazio na cultura da imagem - entre a clínica e a educação. Pro-Posições, 25(1), 161-179. doi: 10.1590/S0103-73072014000100009

Rodrigues, J. M. \& Peixoto Junior, C. A. (2014). Reflexões sobre conceitos afirmativos de saúde e doença nas teorias de Georges Canguilhem e Donald Winnicott. Physis: Revista de Saúde Coletiva, 24(1), 291-310. doi: 10.1590/S0103-73312014000100016

Rolnik, S. (2002). Subjetividade em obra: Lygia Clark, artista contemporânea. Projeto História, 24, 43-54. Recuperado de https://revistas.pucsp.br/index.php/revph/art icle/view/10571 
Sennett, R. (1999). A corrosão do caráter: as consequências pessoais do trabalho no novo capitalismo. Rio de Janeiro: Record.

Silva Sobrinho, J. G. (2015). A perspectiva do cuidado na psicanálise do século XXI. Revista Leitura Flutuante, 7(2), 51-61. Recuperado de https://revistas.pucsp.br/index.php/leiturafl utuante/article/view/25901

Ventura, R. (2012). A psicanálise e o cuidado de si: entre a sujeição e a liberdade. Revista Epos, 3(2). Recuperado de http://pepsic.bvsalud.org/scielo.php?script $=$ sci_arttext\&pid=S2178700X2012000200003

Winnicott, D. (1983). A capacidade para estarsó. In D. Winnicott. $O$ ambiente e os processos de maturação: estudos sobre a teoria do desenvolvimento emocional. Porto Alegre: Artmed.

Winnicott, D. (2011). Tudo começa em casa (5. ed.). São Paulo: Editora WMF Martins Fontes.

\section{Dados sobre os autores:}

- Letícia de Deus Bender: Graduada em psicologia pelo Centro Universitário Metodista IPA. Residente de psicologia do programa de saúde da família e comunidade do Grupo Hospitalar Conceição.

- Cleber Gibbon Ratto: Pesquisador do CNPq - Bolsista de Produtividade. Doutor em Educação. Pesquisador do PPGEDU/UNILASALLE. Psicólogo pela Universidade Católica de Pelotas. Psicoterapeuta. Membro do Centro de Estudos Psicanalíticos de Porto Alegre (CEPdePA). Doutor em Educação pela Pontifícia Universidade Católica do Rio Grande do Sul (PUCRS). 